\title{
Cell-specific modulation of plasticity and cortical state by cholinergic inputs to the visual cortex
}

\author{
Hiroki Sugihara ${ }^{1,4}$, Naiyan Chen $^{2-4}$ and Mriganka Sur ${ }^{1, *}$ \\ ${ }^{1}$ Picower Institute for Learning and Memory, Department of Brain and Cognitive Sciences, \\ Massachusetts Institute of Technology, Cambridge, MA 02139, USA. \\ ${ }^{2}$ McGovern Institute for Brain Research, Massachusetts Institute of Technology, Cambridge, \\ MA 02139, USA. \\ ${ }^{3}$ Laboratory of Metabolic Medicine, Singapore Bioimaging Consortium, A*STAR, Republic of \\ Singapore.
}

${ }^{4}$ These authors contributed equally to this work.

* To whom correspondence should be addressed:

E-mail: $\underline{\text { msur@mit.edu }}$

Phone: 617-253-8784

Fax: 617-253-9829 


\begin{abstract}
Acetylcholine (ACh) modulates diverse vital brain functions. It innervates a wide range of cortical areas, including the primary visual cortex (V1), and multiple cortical cell types have been found to be responsive to ACh. Here we review how different cell types contribute to different cortical functions modulated by ACh. We specifically focus on two major cortical functions: plasticity and cortical state. In layer II/III of V1, ACh acting on astrocytes and somatostatin-expressing inhibitory neurons plays critical roles in these functions. Cell type specificity of cholinergic modulation points towards the growing understanding that even diffuse neurotransmitter systems can mediate specific functions through specific cell classes and receptors.
\end{abstract}

\title{
KEYWORDS
}

astrocytes, inhibitory neurons, somatostatin interneurons, potentiation, decorrelation, desynchronization 


\section{INTRODUCTION}

The primary visual cortex (V1) is a powerful model system for studying how 'bottom-up' sensory experience can be modulated by 'top-down' neurotransmitter processes. In particular, it is densely innervated by afferent cholinergic projections originating in the basal forebrain (BF) which includes the nucleus basalis and the nucleus of the diagonal band of Broca (Do et al., 2016; Kitt et al., 1994; Laplante et al., 2005; Luiten et al., 1987), an area conceptualized as a critical component of 'top-down' processes (Sarter et al., 2001). The distribution of cholinergic axons have been shown to be diffuse (Eckenstein et al., 1988; Rye et al., 1984) and vary in density across the cortical layers (Lysakowski et al., 1989; Mesulam et al., 1992; Raghanti et al., 2008; Satoh et al., 1983). This, coupled with differential expression of muscarinic (mAChRs) and nicotinic acetylcholine receptors (nAChRs) across cortical layers and cell-types (Clarke et al., 1985; Groleau et al., 2015; Zilles et al., 1989), can lead to specific modulation of distinct cortical circuits that orchestrate different brain functions.

Diverse vital brain functions known to be regulated by cholinergic modulation of the neocortex include arousal (Phillis, 1968), attention (Herrero et al., 2008), information processing (Bhattacharyya et al., 2013; Disney et al., 2007; Goard and Dan, 2009; Kosovicheva et al., 2012; Soma et al., 2013), learning and memory (Dotigny et al., 2008; Hasselmo, 2006) and cortical plasticity (Bear and Singer, 1986; Froemke et al., 2007; Kang et al., 2014a; Kang and Vaucher, 2009). The ability of a single cholinergic system to modulate such diverse brain functions, each occurring at specific and distinct timescales, can perhaps be attributed to its specific modulation of varied cell classes that form distinct cortical circuits.

Multiple cortical cell types have been found to be responsive to acetylcholine (ACh). These cells have complex functional interactions, as supported by observations of both 
hyperpolarizing and depolarizing responses in excitatory neurons (Arroyo et al., 2012; Bandrowski et al., 2001; Gulledge and Stuart, 2005; McCormick and Prince, 1986) and different subtypes of inhibitory neurons (Arroyo et al., 2012; Kawaguchi, 1997; Xiang et al., 1998) across distinct neocortical layers in multiple species. A recent study also reveals that ACh can elicit facilitatory and suppressive responses in non fast-spiking (FS) and FS cortical interneurons, respectively (Arroyo et al., 2012).

In the following two sections, we will review specific examples of how cortical circuits comprising excitatory neurons, various inhibitory neuron subtypes, and astrocytes, respond to cholinergic modulation. Specifically, we will focus on two major cholinergic functions: cortical plasticity and state-dependent temporal dynamics of cortical activity. We will discuss cell type specificity for each function and propose functional microcircuits by which ACh elicits these actions.

\section{PLASTICITY}

One of the earliest studies showing that $\mathrm{ACh}$ can induce long-lasting changes in the excitability of neurons was performed by pairing ACh iontophoresis with intracellular depolarization of cortical neurons in awake cats (Woody et al., 1978). Subsequent studies have shown that co-application of ACh or muscarinic agonists with glutamate can induce a prolonged increase in response to glutamate in somatosensory cortical neurons (Lin and Phillis, 1991; Metherate et al., 1987). When the application of ACh or electrical stimulation of BF is paired with sensory stimulation in the somatosensory (Donoghue and Carroll, 1987; Howard III and Simons, 1994; Lamour et al., 1988; Metherate et al., 1987; Rasmusson and Dykes, 1988; Tremblay et al., 1990a, b), auditory cortex (Bakin and Weinberger, 1996; Dimyan and 
Weinberger, 1999; Edeline et al., 1994; Kilgard and Merzenich, 1998a, b; Kilgard et al., 2001), and visual cortex (Kang et al., 2014a; Kang et al., 2015), prolonged enhanced responses to the paired sensory stimuli are observed, often along with changes in behavior (Kang et al., 2014b). These studies have also revealed that cholinergic antagonists cannot reverse the prolonged changes, thereby confirming that the induction but not maintenance of prolonged changes requires ACh (Lamour et al., 1988). It is worth mentioning that cortical plasticity can occur at both single cell and cortical map levels (Bakin and Weinberger, 1996; Bao et al., 2003; Froemke et al., 2007; Kilgard and Merzenich, 1998a; Puckett et al., 2007). There are also other forms of cholinergic modulation of cortical responses, including nicotinic ACh receptor mediated experience dependent plasticity (Morishita et al., 2010), associative fear learning (Letzkus et al., 2011), and behavior state dependent gain control (Fu et al., 2014). In this section, we focus on BF-mediated cholinergic plasticity in adult cortex.

In V1, modulation by ACh and cholinergic drive from the BF in particular are known to result in an enhancement of direction and orientation selectivity in anesthetized animals (Murphy and Sillito, 1991; Sato et al., 1987; Sillito and Kemp, 1983; Zinke et al., 2006), increase in attentional modulation of V1 neurons in behaving monkeys (Herrero et al., 2008), and alteration in the reliability and synchrony of stimulus evoked spikes in V1 neurons (Goard and Dan, 2009). More broadly, responses of V1 neurons to specific visual stimulus features also exhibit pronounced plasticity, and in particular depend on the history of visual stimulation (Dragoi et al., 2000). The potential mechanisms underlying such stimulus-specific plasticity were not examined previously, but now our work and that of others has revealed a significant contribution from cholinergic inputs acting on astrocytes to influence prolonged changes in neuronal responses. 
Cortical astrocytes are an integral component of V1 circuits because they are visually responsive and are capable of modulating visually driven neuronal responses (Schummers et al., 2008). Astrocytes are also involved in the regulation of the microvasculature (Girouard and Iadecola, 2006; Iadecola and Nedergaard, 2007; Vaucher and Hamel, 1995), and couple neuronal responses to hemodynamic signals that underlie functional imaging (Schummers et al., 2008). In the hippocampus, the circuitry of cholinergic modulation includes astrocytes (Haydon, 2001; Nedergaard et al., 2003), which have been discovered to be ACh-responsive (Araque et al., 2002; Perea and Araque, 2005; Shelton and McCarthy, 2000). Ex vivo studies implicate hippocampal astrocytes in synaptic potentiation [(Henneberger et al., 2010; Perea and Araque, 2007; Yang et al., 2003) compare with (Agulhon et al., 2010)], demonstrating that they can potentially provide a powerful mean of altering neuronal networks to induce response plasticity. More recently, our work (Chen et al., 2012), together with others (Navarrete et al., 2012; Takata et al., 2011), has revealed that BF-induced astrocytic activation can induce potentiation of local field potentials (LFP) recorded in the cortex and hippocampus.

To investigate the possible role of astrocytes in cholinergic plasticity of V1 responses, we measured neuronal as well as astrocyte activity while electrically stimulating the BF (Chen et al., 2012). Using cell-attached recordings in vivo, we demonstrated that electrical stimulation of the $\mathrm{BF}$, paired with visual stimulation, can induce significant potentiation of visual responses in excitatory neurons of mouse V1 (Fig. 1). We further showed with in vivo two-photon calcium imaging, ex vivo calcium imaging, and whole-cell recordings that this pairing-induced potentiation is mediated by direct cholinergic activation of V1 astrocytes via muscarinic AChRs. In conditional inositol 1,4,5 trisphosphate receptor type $2 \mathrm{KO}\left(\mathrm{IP}_{3} \mathrm{R} 2\right.$-cKO) mice, which lack astrocyte calcium activation, the potentiation is absent, suggesting a critical contribution of 
astrocytes to this plasticity. The potentiation is also stimulus-specific, because pairing $\mathrm{BF}$ stimulation with a specific visual orientation revealed a highly selective potentiation of responses to the paired orientation compared with unpaired orientations. Collectively, these findings reveal a unique and surprising role for astrocytes in BF-induced stimulus specific plasticity in the cerebral cortex.

How do astrocytes evoke sensory stimulus specific cholinergic potentiation? Or, more specifically, how does $\mathrm{IP}_{3} \mathrm{R} 2$ mediated $\mathrm{Ca}^{2+}$ pathway evoked by $\mathrm{ACh}$ through $\mathrm{mAChRs}$ in astrocytes induce synaptic plasticity in nearby neurons activated by a sensory stimulus? Possible mechanisms include: 1) astrocytic release of glutamate, D-serine, or other gliotransmitter (Parpura and Zorec, 2010; Volterra and Meldolesi, 2005), or 2) regulation of extracellular transmitters (Pannasch et al., 2014) or potassium (Wang et al., 2012), possibly through modulation of transporters in the astrocyte membrane (Bazargani and Attwell, 2016). Future investigation is required to dissect these possibilities, including interaction between astrocytic $\mathrm{Ca}^{2+}$ pathways in somata and processes (Bazargani and Attwell, 2016).

\section{CORTICAL STATE}

Another major function of cholinergic modulation is cortical state change, such as attention (Harris and Thiele, 2011). A wealth of studies using BF lesions, and BF electrical stimulation and pharmacology, have presented rich evidence in support of cholinergic modulation of the detection, selection and processing of stimuli, particularly during attention.

Some of the earliest evidence revealing the role of ACh in information processing came from BF lesion studies. In these studies, selective excitotoxic lesions of the BF neurons were performed by injecting excitatory amino acid agonists or immunotoxins into the BF (Wenk, 
1997). Animals with their BF neurons impaired by this method showed reduced attentional functions (McGaughy et al., 2002; Muir et al., 1993; Robbins et al., 1989; Turchi and Sarter, 1997; Voytko et al., 1994) and stimulus processing abilities (Chiba et al., 1995), as reflected by lower accuracy and longer latencies in their response to attentional tasks. Pharmacological studies using cholinergic receptor agonists and antagonists as well as with cholinesterase inhibitors to enhance or suppress cholinergic action have provided further understanding of the mechanisms. Particularly, researchers have demonstrated that both nicotinic and muscarinic receptors can mediate the change in performance during cholinergic modulation of sensory processing (Hutchison et al., 2001; Stough, 1998; Stough et al., 1995; Thompson et al., 2000) and attentional tasks (Bauer et al., 2012; Furey et al., 2008; Herrero et al., 2008; Thienel et al., 2009).

The advent of single and multi-unit recording has allowed further understanding of cholinergic modulation of information processing at a single neuronal level. These studies typically involve recording of the spike responses of a population of single units before, during and after local iontophoretic application of ACh or electrical stimulation of the BF. In sensory cortex, these studies have shown that cholinergic modulation can affect contrast gain (Bhattacharyya et al., 2013; Disney et al., 2007; Soma et al., 2013), orientation and direction selectivity (Herrero et al., 2008; Muller and Singer, 1989; Sato et al., 1987; Sillito and Kemp, 1983; Thiele et al., 2012), spatial integration (Roberts et al., 2005), receptive field size (Bakin and Weinberger, 1996; Kilgard and Merzenich, 1998a) and attention (Herrero et al., 2008).

More recently, similar studies performed with more elegant analyses have also revealed that ACh can enhance information processing through interneuronal decorrelation of V1 responses (Goard and Dan, 2009; Thiele, 2009). Such decorrelation between V1 responses is 
particularly evident during execution of attentional tasks in behaving monkeys (Cohen and Maunsell, 2009; Mitchell et al., 2009).

Several studies have shown that the cholinergic system can control cortical states. ACh release in the cortex has been observed to co-vary with brain state changes (Marrosu et al., 1995), while increased BF neuronal firing has been found to occur during cortical desynchronization (Duque et al., 2000; Manns et al., 2000). The causal relationship between the cholinergic system and cortical states are further established in a range of studies. Lesions of the BF lead to increased low-frequency LFP power (Buzsaki et al., 1988), indicating more synchronized neural activities, while electrical and optogenetic stimulation of the basal forebrain or of cholinergic projections to the cortex induces mAChR-mediated cortical desynchronization, including decreased low-frequency and increased high-frequency LFP power (Kalmbach et al., 2012; Metherate et al., 1992). This ACh-induced desynchronization is similar to that observed during normal physiological changes (Kalmbach et al., 2012).

These related phenomena (Harris and Thiele, 2011), viz. neuronal decorrelation and LFP desynchronization, are proposed to enhance information processing in alert, active and attentive conditions (Cohen and Maunsell, 2009; Herrero et al., 2013; Herrero et al., 2008; Mitchell et al., 2009; Singer, 1993). Thus, ACh can change the temporal dynamics of cortex by shifting cortical state from a correlated or synchronized state to a decorrelated or desynchronized state, and consequently enhance cortical information processing. Recent computational studies have suggested that inhibitory neurons can drive decorrelation and sparse coding in the cortex (De La Rocha et al., 2007; King et al., 2013), and experimental evidence shows that inhibitory neuronal activity correlates with (Klausberger et al., 2003) and can induce (Avella Gonzalez et al., 2012; Cardin et al., 2009) specific neuronal activity patterns. Furthermore, subtypes of inhibitory 
neurons differentially express nicotinic and muscarinic ACh receptors, suggesting possible distinct cholinergic modulation of their microcircuits (Arroyo et al., 2014; Porter et al., 1999; Xiang et al., 1998).

To investigate the possible role of ACh inputs to cortex and inhibitory neurons in temporal activity modulation, we measured the neural activity of each inhibitory neuron type while optogenetically stimulating superficial cholinergic axons in mouse V1 (Chen et al., 2015). We found that intracortical cholinergic inputs specifically and differentially drive a defined functional cortical microcircuit in superficial layers of mouse V1 to cause ACh driven desynchronization: they facilitate somatostatin-expressing (SOM) inhibitory neurons that in turn inhibit parvalbumin-expressing (PV) inhibitory neurons and pyramidal neurons. Selective optogenetic inhibition of SOM neurons blocks desynchronization of the LFP and decorrelation of neural responses induced by cholinergic stimulation (Fig. 2a, b). This demonstrates that direct cholinergic activation of SOM neurons is necessary for this phenomenon. Furthermore, direct optogenetic activation of SOM neurons, independent of cholinergic modulation, is sufficient to induce desynchronization. Together, these findings demonstrate a crucial role of cholinergic drive to specific inhibitory-excitatory circuits in actively shaping the dynamics of neuronal activity (Fig. 2c).

Among other subtypes of inhibitory neurons, vasoactive intestinal peptide-expressing (VIP) and layer 1 (L1) inhibitory neurons have also been reported to respond to cholinergic modulation (Alitto and Dan, 2012; Arroyo et al., 2014; Fu et al., 2014; Kawaguchi, 1997; Letzkus et al., 2011). These subtypes of inhibitory neurons respond to higher ACh concentrations compared to SOM neurons: in V1 slices, SOM neurons start to respond to ACh at lower concentrations (1-100 $\mu \mathrm{M})$, consistent with their low-threshold spiking properties (Fanselow et 
al., 2008), whereas VIP and L1 neurons require higher concentration (10 mM) (Chen et al., 2015). In addition, they affect excitatory neurons differently during cholinergic modulation. Upon application of $\mathrm{ACh}$ in slices, excitatory neurons receive massive inhibitory input, which mostly arises from SOM neurons since these inhibitory inputs are abolished by suppressing activities of SOM neurons optogenetically. In contrast, suppression of VIP or L1 inhibitory neurons does not alter inhibitory inputs to excitatory neurons upon ACh application, despite these neurons being activated at high levels of cholinergic drive. Furthermore, optogenetic inhibition of VIP neurons in vivo does not block LFP desynchronization. These results indicate that, although VIP and L1 inhibitory neurons respond to cholinergic input, they do not play a major role in cortical functional circuits for desynchronization.

VIP neurons almost exclusively inhibit SOM neurons in layer II/III of mouse visual cortex, whereas SOM neurons strongly inhibit VIP neurons (Pfeffer et al., 2013). Some studies suggest suppressed responses of SOM neurons via inhibition from VIP neurons (Fu et al., 2014; Karnani et al., 2016; Pi et al., 2013), whereas others have reported that ACh activates SOM neurons (Chen et al., 2015; Kawaguchi, 1997; Kocharyan et al., 2008; Xu et al., 2013). Given the differential ACh concentration dependency between VIP/L1 neurons and SOM neurons, and mutual inhibition between VIP and SOM neurons, it is possible that these inhibitory neuron subtypes act as a switch between different functional microcircuits depending on cholinergic input level. While SOM neurons are activated by ACh and cause cortical state change such as arousal/attention, VIP/L1 neurons may contribute to functions requiring higher cholinergic drive such as gain control during locomotion (Fu et al., 2014) or associative fear learning (Letzkus et al., 2011). 


\section{CONCLUSIONS}

We have reviewed how ACh can engage specific cortical circuits that operate at distinct timescales to modulate two different brain functions: response plasticity of single neurons, and response dynamics of neuronal populations. Specifically, ACh acts on circuits comprising astrocytes and pyramidal neurons to modulate visual cortical plasticity that occurs at a prolonged timescale (tens of seconds to minutes). ACh acts on circuits comprising inhibitory neuronal subtypes and pyramidal neurons to modulate cortical state changes and information processing over a more transient timescale (milliseconds to seconds). These two functional microcircuits are distinguished by their distinct timescales and their recruitment of different cell types. However, while repeated pairing with $\mathrm{BF}$ and sensory stimulation is required for cholinergic plasticity, the microcircuit required for cortical state change will also be evoked at each BF stimulation. Thus, the functional microcircuit for desynchronization may affect cholinergic plasticity, probably through improvement of sensory stimulus selectivity. Furthermore, although the timescale of these brain functions seem to match respectively the slow timescale of astrocytes (LopezHidalgo and Schummers, 2014) and fast timescale of inhibitory neurons (Butts et al., 2007), it may be possible for the engagement of astrocytes and inhibitory neurons to overlap and for both cell types to be involved in cholinergic modulated learning and plasticity: the 'faster' inhibitory neurons can initiate plasticity via disinhibition (Sur et al., 2013) while the 'slower' astrocytes can consolidate the phenomenon. For example, in gain modulation with associative fear learning (Letzkus et al., 2011) or during locomotion (Fu et al., 2014), VIP/L1 neurons modulate cortical gain via disinhibition through nicotinic ACh receptors, and such repetitive gain modulation can be further facilitated and consolidated by ACh-activated astrocytes through their muscarinic ACh 
receptors. Further investigation will be necessary to uncover the mechanisms that underlie possible interaction between astrocytes and inhibitory neurons during cholinergic modulation.

The proposed microcircuits described in our studies are derived from studies using the superficial layers of the mouse visual cortex as a model. The common principles derived from these findings can potentially apply to other cortical layers, brain regions and species. However, the exact mechanisms may differ across regions and species due to varying density and distribution of cholinergic axons across cortical layers (Lysakowski et al., 1989; Mesulam et al., 1992; Raghanti et al., 2008; Satoh et al., 1983), and differential expression of muscarinic and nicotinic ACh receptors across cortical layers and cell-types (Clarke et al., 1985; Groleau et al., 2015; Zilles et al., 1989). For example, VIP neurons inhibit PV neurons in the superficial layers of mouse auditory cortex (Letzkus et al., 2011; Pi et al., 2013), whereas such inhibition is not clearly observed in the visual cortex (Karnani et al., 2016; Pfeffer et al., 2013). Furthermore, cortical projections of BF are topographically organized (Zaborszky et al., 2015) and cholinergic modulation can be cortical area specific (Chaves-Coira et al., 2016; Golmayo et al., 2003; Rasmusson et al., 2007). Thus, cholinergic modulation can be task specific and also different tasks with varied cholinergic load could activate distinct cortical circuits (Chen et al., 2015).

The cholinergic system from the BF that innervates the neocortex was previously found to be implicated in arousal (Phillis, 1968) and attention (Arnold et al., 2002; Dalley et al., 2001; Herrero et al., 2008; Himmelheber et al., 2000; McGaughy et al., 2002; Parikh et al., 2007; Passetti et al., 2000) using rats, monkeys and cats as research models. However, a recent study (Hangya et al., 2015) has revealed that a non-cholinergic basal forebrain population (but not cholinergic neurons) was correlated with trial-to-trial measures of sustained attention in mice performing an auditory detection task. Furthermore, cortically projecting PV neurons in BF may 
innervate cortical PV neurons and modify gamma band oscillations (Kim et al., 2015) or wakefulness (Anaclet et al., 2015; Zant et al., 2016). These studies open the question of whether there are differences between cholinergic modulation and BF modulation of the neocortex (Avila and Lin, 2014). Future detailed analysis of region, task, and species-specific cholinergic mechanisms is therefore important for revealing definitive answers to these questions.

\section{ACKNOWLEDGEMENTS}

This work was supported by grants from the NIH (U01NS090473, R01EY007023), NSF (EF1451125), the Simons Foundation Autism Research Initiative, and the Picower Institute Innovation Fund (MS). 


\section{REFERENCES}

Agulhon, C., Fiacco, T.A., McCarthy, K.D., 2010. Hippocampal short- and long-term plasticity are not modulated by astrocyte $\mathrm{Ca}^{2+}$ signaling. Science 327(5970), 1250-1254.

Alitto, H.J., Dan, Y., 2012. Cell-type-specific modulation of neocortical activity by basal forebrain input. Front. Syst. Neurosci. 6, 79.

Anaclet, C., Pedersen, N.P., Ferrari, L.L., Venner, A., Bass, C.E., Arrigoni, E., Fuller, P.M., 2015. Basal forebrain control of wakefulness and cortical rhythms. Nat. Commun. 6, 8744.

Araque, A., Martin, E.D., Perea, G., Arellano, J.I., Buno, W., 2002. Synaptically released acetylcholine evokes $\mathrm{Ca}^{2+}$ elevations in astrocytes in hippocampal slices. J. Neurosci. 22(7), 2443-2450.

Arnold, H.M., Burk, J.A., Hodgson, E.M., Sarter, M., Bruno, J.P., 2002. Differential cortical acetylcholine release in rats performing a sustained attention task versus behavioral control tasks that do not explicitly tax attention. Neuroscience 114(2), 451-460.

Arroyo, S., Bennett, C., Aziz, D., Brown, S.P., Hestrin, S., 2012. Prolonged disynaptic inhibition in the cortex mediated by slow, non- $\alpha 7$ nicotinic excitation of a specific subset of cortical interneurons. J. Neurosci. 32(11), 3859-3864.

Arroyo, S., Bennett, C., Hestrin, S., 2014. Nicotinic modulation of cortical circuits. Front. Neural Circuits 8, 30.

Avella Gonzalez, O.J., van Aerde, K.I., van Elburg, R.A., Poil, S.S., Mansvelder, H.D., Linkenkaer-Hansen, K., van Pelt, J., van Ooyen, A., 2012. External drive to inhibitory cells induces alternating episodes of high- and low-amplitude oscillations. PLoS Comput. Biol. 8(8), e1002666.

Avila, I., Lin, S.C., 2014. Distinct neuronal populations in the basal forebrain encode motivational salience and movement. Front. Behav. Neurosci. 8, 421.

Bakin, J.S., Weinberger, N.M., 1996. Induction of a physiological memory in the cerebral cortex by stimulation of the nucleus basalis. Proc. Natl. Acad. Sci. U. S. A. 93(20), 11219-11224.

Bandrowski, A.E., Moore, S.L., Ashe, J.H., 2001. Cholinergic synaptic potentials in the supragranular layers of auditory cortex. Synapse 41(2), 118-130.

Bao, S., Chang, E.F., Davis, J.D., Gobeske, K.T., Merzenich, M.M., 2003. Progressive degradation and subsequent refinement of acoustic representations in the adult auditory cortex. J. Neurosci. 23(34), 10765-10775.

Bauer, M., Kluge, C., Bach, D., Bradbury, D., Heinze, H.J., Dolan, R.J., Driver, J., 2012. Cholinergic enhancement of visual attention and neural oscillations in the human brain. Curr. Biol. 22(5), 397-402.

Bazargani, N., Attwell, D., 2016. Astrocyte calcium signaling: the third wave. Nat. Neurosci. 19(2), 182-189.

Bear, M.F., Singer, W., 1986. Modulation of visual cortical plasticity by acetylcholine and noradrenaline. Nature 320(6058), 172-176.

Bhattacharyya, A., Veit, J., Kretz, R., Bondar, I., Rainer, G., 2013. Basal forebrain activation controls contrast sensitivity in primary visual cortex. BMC Neurosci. 14, 55.

Butts, D.A., Weng, C., Jin, J., Yeh, C.I., Lesica, N.A., Alonso, J.M., Stanley, G.B., 2007. Temporal precision in the neural code and the timescales of natural vision. Nature 449(7158), 92-95. 
Buzsaki, G., Bickford, R.G., Ponomareff, G., Thal, L.J., Mandel, R., Gage, F.H., 1988. Nucleus basalis and thalamic control of neocortical activity in the freely moving rat. J. Neurosci. 8(11), 4007-4026.

Cardin, J.A., Carlen, M., Meletis, K., Knoblich, U., Zhang, F., Deisseroth, K., Tsai, L.H., Moore, C.I., 2009. Driving fast-spiking cells induces gamma rhythm and controls sensory responses. Nature 459(7247), 663-667.

Chaves-Coira, I., Barros-Zulaica, N., Rodrigo-Angulo, M., Nunez, A., 2016. Modulation of Specific Sensory Cortical Areas by Segregated Basal Forebrain Cholinergic Neurons Demonstrated by Neuronal Tracing and Optogenetic Stimulation in Mice. Front. Neural Circuits $10,28$.

Chen, N., Sugihara, H., Sharma, J., Perea, G., Petravicz, J., Le, C., Sur, M., 2012. Nucleus basalis-enabled stimulus-specific plasticity in the visual cortex is mediated by astrocytes. Proc. Natl. Acad. Sci. U. S. A. 109(41), E2832-2841.

Chen, N., Sugihara, H., Sur, M., 2015. An acetylcholine-activated microcircuit drives temporal dynamics of cortical activity. Nat. Neurosci. 18(6), 892-902.

Chiba, A.A., Bucci, D.J., Holland, P.C., Gallagher, M., 1995. Basal forebrain cholinergic lesions disrupt increments but not decrements in conditioned stimulus processing. J. Neurosci. 15(11), 7315-7322.

Clarke, P.B., Schwartz, R.D., Paul, S.M., Pert, C.B., Pert, A., 1985. Nicotinic binding in rat brain: autoradiographic comparison of $\left[{ }^{3} \mathrm{H}\right]$ acetylcholine, $\left[{ }^{3} \mathrm{H}\right]$ nicotine, and $\left[{ }^{125} \mathrm{I}\right]-\alpha-$ bungarotoxin. J. Neurosci. 5(5), 1307-1315.

Cohen, M.R., Maunsell, J.H., 2009. Attention improves performance primarily by reducing interneuronal correlations. Nat. Neurosci. 12(12), 1594-1600.

Dalley, J.W., McGaughy, J., O'Connell, M.T., Cardinal, R.N., Levita, L., Robbins, T.W., 2001. Distinct changes in cortical acetylcholine and noradrenaline efflux during contingent and noncontingent performance of a visual attentional task. J. Neurosci. 21(13), 4908-4914.

De La Rocha, J., Doiron, B., Eric Shea-Brown, K.J., cacute, Reyes, A., 2007. Correlation between neural spike trains increases with firing rate. Nature 448(7155), 802-806.

Dimyan, M.A., Weinberger, N.M., 1999. Basal forebrain stimulation induces discriminative receptive field plasticity in the auditory cortex. Behav. Neurosci. 113(4), 691-702.

Disney, A.A., Aoki, C., Hawken, M.J., 2007. Gain modulation by nicotine in macaque v1. Neuron 56(4), 701-713.

Do, J.P., Xu, M., Lee, S.H., Chang, W.C., Zhang, S., Chung, S., Yung, T.J., Fan, J.L., Miyamichi, K., Luo, L., Dan, Y., 2016. Cell type-specific long-range connections of basal forebrain circuit. eLife 5.

Donoghue, J.P., Carroll, K.L., 1987. Cholinergic modulation of sensory responses in rat primary somatic sensory cortex. Brain Res. 408(1-2), 367-371.

Dotigny, F., Ben Amor, A.Y., Burke, M., Vaucher, E., 2008. Neuromodulatory role of acetylcholine in visually-induced cortical activation: behavioral and neuroanatomical correlates. Neuroscience 154(4), 1607-1618.

Dragoi, V., Sharma, J., Sur, M., 2000. Adaptation-induced plasticity of orientation tuning in adult visual cortex. Neuron 28(1), 287-298.

Duque, A., Balatoni, B., Detari, L., Zaborszky, L., 2000. EEG correlation of the discharge properties of identified neurons in the basal forebrain. J. Neurophysiol. 84(3), 1627-1635.

Eckenstein, F.P., Baughman, R.W., Quinn, J., 1988. An anatomical study of cholinergic innervation in rat cerebral cortex. Neuroscience 25(2), 457-474. 
Edeline, J.M., Hars, B., Maho, C., Hennevin, E., 1994. Transient and prolonged facilitation of tone-evoked responses induced by basal forebrain stimulations in the rat auditory cortex. Exp. Brain Res. 97(3), 373-386.

Fanselow, E.E., Richardson, K.A., Connors, B.W., 2008. Selective, state-dependent activation of somatostatin-expressing inhibitory interneurons in mouse neocortex. J. Neurophysiol. 100(5), 2640-2652.

Froemke, R.C., Merzenich, M.M., Schreiner, C.E., 2007. A synaptic memory trace for cortical receptive field plasticity. Nature 450(7168), 425-429.

Fu, Y., Tucciarone, J.M., Espinosa, J.S., Sheng, N., Darcy, D.P., Nicoll, R.A., Huang, Z.J., Stryker, M.P., 2014. A cortical circuit for gain control by behavioral state. Cell 156(6), 11391152.

Furey, M.L., Pietrini, P., Haxby, J.V., Drevets, W.C., 2008. Selective effects of cholinergic modulation on task performance during selective attention. Neuropsychopharmacology 33(4), 913-923.

Girouard, H., Iadecola, C., 2006. Neurovascular coupling in the normal brain and in hypertension, stroke, and Alzheimer disease. J Appl Physiol (1985) 100(1), 328-335.

Goard, M., Dan, Y., 2009. Basal forebrain activation enhances cortical coding of natural scenes. Nat. Neurosci. 12(11), 1444-1449.

Golmayo, L., Nunez, A., Zaborszky, L., 2003. Electrophysiological evidence for the existence of a posterior cortical-prefrontal-basal forebrain circuitry in modulating sensory responses in visual and somatosensory rat cortical areas. Neuroscience 119(2), 597-609.

Groleau, M., Kang, J.I., Huppe-Gourgues, F., Vaucher, E., 2015. Distribution and effects of the muscarinic receptor subtypes in the primary visual cortex. Frontiers in synaptic neuroscience 7 , 10.

Gulledge, A.T., Stuart, G.J., 2005. Cholinergic inhibition of neocortical pyramidal neurons. J. Neurosci. 25(44), 10308-10320.

Hangya, B., Ranade, S.P., Lorenc, M., Kepecs, A., 2015. Central Cholinergic Neurons Are Rapidly Recruited by Reinforcement Feedback. Cell 162(5), 1155-1168.

Harris, K.D., Thiele, A., 2011. Cortical state and attention. Nat. Rev. Neurosci. 12(9), 509-523. Hasselmo, M.E., 2006. The role of acetylcholine in learning and memory. Curr. Opin. Neurobiol. 16(6), 710-715.

Haydon, P.G., 2001. GLIA: listening and talking to the synapse. Nat. Rev. Neurosci. 2(3), 185193.

Henneberger, C., Papouin, T., Oliet, S.H., Rusakov, D.A., 2010. Long-term potentiation depends on release of D-serine from astrocytes. Nature 463(7278), 232-236.

Herrero, J.L., Gieselmann, M.A., Sanayei, M., Thiele, A., 2013. Attention-induced variance and noise correlation reduction in macaque V1 is mediated by NMDA receptors. Neuron 78(4), 729739.

Herrero, J.L., Roberts, M.J., Delicato, L.S., Gieselmann, M.A., Dayan, P., Thiele, A., 2008. Acetylcholine contributes through muscarinic receptors to attentional modulation in V1. Nature 454(7208), 1110-1114.

Himmelheber, A.M., Sarter, M., Bruno, J.P., 2000. Increases in cortical acetylcholine release during sustained attention performance in rats. Brain Res. Cogn. Brain Res. 9(3), 313-325.

Howard III, M.A., Simons, D.J., 1994. Physiologic effects of nucleus basalis magnocellularis stimulation on rat barrel cortex neurons. Exp. Brain Res. 102(1), 21-33. 
Hutchison, C.W., Nathan, P.J., Mrazek, L., Stough, C., 2001. Cholinergic modulation of speed of early information processing: the effect of donepezil on inspection time. Psychopharmacology (Berl). 155(4), 440-442.

Iadecola, C., Nedergaard, M., 2007. Glial regulation of the cerebral microvasculature. Nat. Neurosci. 10(11), 1369-1376.

Kalmbach, A., Hedrick, T., Waters, J., 2012. Selective optogenetic stimulation of cholinergic axons in neocortex. J. Neurophysiol. 107(7), 2008-2019.

Kang, J.I., Groleau, M., Dotigny, F., Giguere, H., Vaucher, E., 2014a. Visual training paired with electrical stimulation of the basal forebrain improves orientation-selective visual acuity in the rat. Brain Struct. Funct. 219(4), 1493-1507.

Kang, J.I., Huppe-Gourgues, F., Vaucher, E., 2014b. Boosting visual cortex function and plasticity with acetylcholine to enhance visual perception. Front. Syst. Neurosci. 8, 172.

Kang, J.I., Huppe-Gourgues, F., Vaucher, E., 2015. Pharmacological Mechanisms of Cortical Enhancement Induced by the Repetitive Pairing of Visual/Cholinergic Stimulation. PLoS ONE 10(10), e0141663.

Kang, J.I., Vaucher, E., 2009. Cholinergic pairing with visual activation results in long-term enhancement of visual evoked potentials. PLoS ONE 4(6), e5995.

Karnani, M.M., Jackson, J., Ayzenshtat, I., Tucciarone, J., Manoocheri, K., Snider, W.G., Yuste, R., 2016. Cooperative Subnetworks of Molecularly Similar Interneurons in Mouse Neocortex. Neuron 90(1), 86-100.

Kawaguchi, Y., 1997. Selective cholinergic modulation of cortical GABAergic cell subtypes. J. Neurophysiol. 78(3), 1743-1747.

Kilgard, M.P., Merzenich, M.M., 1998a. Cortical map reorganization enabled by nucleus basalis activity. Science 279(5357), 1714-1718.

Kilgard, M.P., Merzenich, M.M., 1998b. Plasticity of temporal information processing in the primary auditory cortex. Nat. Neurosci. 1(8), 727-731.

Kilgard, M.P., Pandya, P.K., Vazquez, J., Gehi, A., Schreiner, C.E., Merzenich, M.M., 2001. Sensory input directs spatial and temporal plasticity in primary auditory cortex. J. Neurophysiol. 86(1), 326-338.

Kim, T., Thankachan, S., McKenna, J.T., McNally, J.M., Yang, C., Choi, J.H., Chen, L., Kocsis, B., Deisseroth, K., Strecker, R.E., Basheer, R., Brown, R.E., McCarley, R.W., 2015. Cortically projecting basal forebrain parvalbumin neurons regulate cortical gamma band oscillations. Proc. Natl. Acad. Sci. U. S. A. 112(11), 3535-3540.

King, P.D., Zylberberg, J., DeWeese, M.R., 2013. Inhibitory interneurons decorrelate excitatory cells to drive sparse code formation in a spiking model of V1. J. Neurosci. 33(13), 5475-5485.

Kitt, C.A., Hohmann, C., Coyle, J.T., Price, D.L., 1994. Cholinergic innervation of mouse forebrain structures. J. Comp. Neurol. 341(1), 117-129.

Klausberger, T., Magill, P.J., Marton, L.F., Roberts, J.D., Cobden, P.M., Buzsaki, G., Somogyi, P., 2003. Brain-state- and cell-type-specific firing of hippocampal interneurons in vivo. Nature 421(6925), 844-848.

Kocharyan, A., Fernandes, P., Tong, X.K., Vaucher, E., Hamel, E., 2008. Specific subtypes of cortical GABA interneurons contribute to the neurovascular coupling response to basal forebrain stimulation. J. Cereb. Blood Flow Metab. 28(2), 221-231.

Kosovicheva, A.A., Sheremata, S.L., Rokem, A., Landau, A.N., Silver, M.A., 2012. Cholinergic enhancement reduces orientation-specific surround suppression but not visual crowding. Front. Behav. Neurosci. 6, 61. 
Lamour, Y., Dutar, P., Jobert, A., Dykes, R.W., 1988. An iontophoretic study of single somatosensory neurons in rat granular cortex serving the limbs: a laminar analysis of glutamate and acetylcholine effects on receptive-field properties. J. Neurophysiol. 60(2), 725-750.

Laplante, F., Morin, Y., Quirion, R., Vaucher, E., 2005. Acetylcholine release is elicited in the visual cortex, but not in the prefrontal cortex, by patterned visual stimulation: a dual in vivo microdialysis study with functional correlates in the rat brain. Neuroscience 132(2), 501-510.

Letzkus, J.J., Wolff, S.B., Meyer, E.M., Tovote, P., Courtin, J., Herry, C., Luthi, A., 2011. A disinhibitory microcircuit for associative fear learning in the auditory cortex. Nature 480(7377), 331-335.

Lin, Y., Phillis, J.W., 1991. Muscarinic agonist-mediated induction of long-term potentiation in rat cerebral cortex. Brain Res. 551(1-2), 342-345.

Lopez-Hidalgo, M., Schummers, J., 2014. Cortical maps: a role for astrocytes? Curr. Opin. Neurobiol. 24(1), 176-189.

Luiten, P.G., Gaykema, R.P., Traber, J., Spencer, D.G., Jr., 1987. Cortical projection patterns of magnocellular basal nucleus subdivisions as revealed by anterogradely transported Phaseolus vulgaris leucoagglutinin. Brain Res. 413(2), 229-250.

Lysakowski, A., Wainer, B.H., Bruce, G., Hersh, L.B., 1989. An atlas of the regional and laminar distribution of choline acetyltransferase immunoreactivity in rat cerebral cortex. Neuroscience 28(2), 291-336.

Manns, I.D., Alonso, A., Jones, B.E., 2000. Discharge properties of juxtacellularly labeled and immunohistochemically identified cholinergic basal forebrain neurons recorded in association with the electroencephalogram in anesthetized rats. J. Neurosci. 20(4), 1505-1518.

Marrosu, F., Portas, C., Mascia, M.S., Casu, M.A., Fa, M., Giagheddu, M., Imperato, A., Gessa, G.L., 1995. Microdialysis measurement of cortical and hippocampal acetylcholine release during sleep-wake cycle in freely moving cats. Brain Res. 671(2), 329-332.

McCormick, D.A., Prince, D.A., 1986. Mechanisms of action of acetylcholine in the guinea-pig cerebral cortex in vitro. J. Physiol. 375(1), 169-194.

McGaughy, J., Dalley, J.W., Morrison, C.H., Everitt, B.J., Robbins, T.W., 2002. Selective behavioral and neurochemical effects of cholinergic lesions produced by intrabasalis infusions of 192 IgG-saporin on attentional performance in a five-choice serial reaction time task. J. Neurosci. 22(5), 1905-1913.

Mesulam, M.M., Hersh, L.B., Mash, D.C., Geula, C., 1992. Differential cholinergic innervation within functional subdivisions of the human cerebral cortex: a choline acetyltransferase study. J. Comp. Neurol. 318(3), 316-328.

Metherate, R., Cox, C.L., Ashe, J.H., 1992. Cellular bases of neocortical activation: modulation of neural oscillations by the nucleus basalis and endogenous acetylcholine. J. Neurosci. 12(12), 4701-4711.

Metherate, R., Tremblay, N., Dykes, R.W., 1987. Acetylcholine permits long-term enhancement of neuronal responsiveness in cat primary somatosensory cortex. Neuroscience 22(1), 75-81.

Mitchell, J.F., Sundberg, K.A., Reynolds, J.H., 2009. Spatial attention decorrelates intrinsic activity fluctuations in macaque area V4. Neuron 63(6), 879-888.

Morishita, H., Miwa, J.M., Heintz, N., Hensch, T.K., 2010. Lynx1, a cholinergic brake, limits plasticity in adult visual cortex. Science 330(6008), 1238-1240.

Muir, J.L., Page, K.J., Sirinathsinghji, D.J., Robbins, T.W., Everitt, B.J., 1993. Excitotoxic lesions of basal forebrain cholinergic neurons: effects on learning, memory and attention. Behav. Brain Res. 57(2), 123-131. 
Muller, C.M., Singer, W., 1989. Acetylcholine-induced inhibition in the cat visual cortex is mediated by a GABAergic mechanism. Brain Res. 487(2), 335-342.

Murphy, P.C., Sillito, A.M., 1991. Cholinergic enhancement of direction selectivity in the visual cortex of the cat. Neuroscience 40(1), 13-20.

Navarrete, M., Perea, G., Fernandez de Sevilla, D., Gomez-Gonzalo, M., Nunez, A., Martin, E.D., Araque, A., 2012. Astrocytes mediate in vivo cholinergic-induced synaptic plasticity. PLoS Biol. 10(2), e1001259.

Nedergaard, M., Ransom, B., Goldman, S.A., 2003. New roles for astrocytes: redefining the functional architecture of the brain. Trends Neurosci. 26(10), 523-530.

Pannasch, U., Freche, D., Dallerac, G., Ghezali, G., Escartin, C., Ezan, P., Cohen-Salmon, M., Benchenane, K., Abudara, V., Dufour, A., Lubke, J.H., Deglon, N., Knott, G., Holcman, D., Rouach, N., 2014. Connexin 30 sets synaptic strength by controlling astroglial synapse invasion. Nat. Neurosci. 17(4), 549-558.

Parikh, V., Kozak, R., Martinez, V., Sarter, M., 2007. Prefrontal acetylcholine release controls cue detection on multiple timescales. Neuron 56(1), 141-154.

Parpura, V., Zorec, R., 2010. Gliotransmission: Exocytotic release from astrocytes. Brain Res. Rev. 63(1-2), 83-92.

Passetti, F., Dalley, J.W., O'Connell, M.T., Everitt, B.J., Robbins, T.W., 2000. Increased acetylcholine release in the rat medial prefrontal cortex during performance of a visual attentional task. Eur. J. Neurosci. 12(8), 3051-3058.

Perea, G., Araque, A., 2005. Properties of synaptically evoked astrocyte calcium signal reveal synaptic information processing by astrocytes. J. Neurosci. 25(9), 2192-2203.

Perea, G., Araque, A., 2007. Astrocytes potentiate transmitter release at single hippocampal synapses. Science 317(5841), 1083-1086.

Pfeffer, C.K., Xue, M., He, M., Huang, Z.J., Scanziani, M., 2013. Inhibition of inhibition in visual cortex: the logic of connections between molecularly distinct interneurons. Nat. Neurosci. 16(8), 1068-1076.

Phillis, J.W., 1968. Acetylcholine release from the cerebral cortex: its role in cortical arousal. Brain Res. 7(3), 378-389.

Pi, H.J., Hangya, B., Kvitsiani, D., Sanders, J.I., Huang, Z.J., Kepecs, A., 2013. Cortical interneurons that specialize in disinhibitory control. Nature 503(7477), 521-524.

Porter, J.T., Cauli, B., Tsuzuki, K., Lambolez, B., Rossier, J., Audinat, E., 1999. Selective excitation of subtypes of neocortical interneurons by nicotinic receptors. J. Neurosci. 19(13), 5228-5235.

Puckett, A.C., Pandya, P.K., Moucha, R., Dai, W., Kilgard, M.P., 2007. Plasticity in the rat posterior auditory field following nucleus basalis stimulation. J. Neurophysiol. 98(1), 253-265.

Raghanti, M.A., Stimpson, C.D., Marcinkiewicz, J.L., Erwin, J.M., Hof, P.R., Sherwood, C.C., 2008. Cholinergic innervation of the frontal cortex: differences among humans, chimpanzees, and macaque monkeys. J. Comp. Neurol. 506(3), 409-424.

Rasmusson, D.D., Dykes, R.W., 1988. Long-term enhancement of evoked potentials in cat somatosensory cortex produced by co-activation of the basal forebrain and cutaneous receptors. Exp. Brain Res. 70(2), 276-286.

Rasmusson, D.D., Smith, S.A., Semba, K., 2007. Inactivation of prefrontal cortex abolishes cortical acetylcholine release evoked by sensory or sensory pathway stimulation in the rat. Neuroscience 149(1), 232-241. 
Robbins, T.W., Everitt, B.J., Marston, H.M., Wilkinson, J., Jones, G.H., Page, K.J., 1989. Comparative effects of ibotenic acid- and quisqualic acid-induced lesions of the substantia innominata on attentional function in the rat: further implications for the role of the cholinergic neurons of the nucleus basalis in cognitive processes. Behav. Brain Res. 35(3), 221-240.

Roberts, M.J., Zinke, W., Guo, K., Robertson, R., McDonald, J.S., Thiele, A., 2005. Acetylcholine dynamically controls spatial integration in marmoset primary visual cortex. J. Neurophysiol. 93(4), 2062-2072.

Rye, D.B., Wainer, B.H., Mesulam, M.M., Mufson, E.J., Saper, C.B., 1984. Cortical projections arising from the basal forebrain: a study of cholinergic and noncholinergic components employing combined retrograde tracing and immunohistochemical localization of choline acetyltransferase. Neuroscience 13(3), 627-643.

Sarter, M., Givens, B., Bruno, J.P., 2001. The cognitive neuroscience of sustained attention: where top-down meets bottom-up. Brain Res. Brain Res. Rev. 35(2), 146-160.

Sato, H., Hata, Y., Masui, H., Tsumoto, T., 1987. A functional role of cholinergic innervation to neurons in the cat visual cortex. J. Neurophysiol. 58(4), 765-780.

Satoh, K., Armstrong, D.M., Fibiger, H.C., 1983. A comparison of the distribution of central cholinergic neurons as demonstrated by acetylcholinesterase pharmacohistochemistry and choline-acetyltransferase immunohistochemistry. Brain Res. Bull. 11(6), 693-720.

Schummers, J., Yu, H., Sur, M., 2008. Tuned responses of astrocytes and their influence on hemodynamic signals in the visual cortex. Science 320(5883), 1638-1643.

Shelton, M.K., McCarthy, K.D., 2000. Hippocampal astrocytes exhibit $\mathrm{Ca}^{2+}$-elevating muscarinic cholinergic and histaminergic receptors in situ. J. Neurochem. 74(2), 555-563.

Sillito, A.M., Kemp, J.A., 1983. Cholinergic modulation of the functional organization of the cat visual cortex. Brain Res. 289(1-2), 143-155.

Singer, W., 1993. Synchronization of cortical activity and its putative role in information processing and learning. Annu. Rev. Physiol. 55(1), 349-374.

Soma, S., Shimegi, S., Suematsu, N., Tamura, H., Sato, H., 2013. Modulation-specific and laminar-dependent effects of acetylcholine on visual responses in the rat primary visual cortex. PLoS ONE 8(7), e68430.

Stough, C., 1998. Nicotine and information processing: Recent studies. Brain topography today. Amsterdam: Elsevier, 799-802.

Stough, C., Mangan, G., Bates, T., Frank, N., Kerkin, B., Pellett, O., 1995. Effects of nicotine on perceptual speed. Psychopharmacology (Berl). 119(3), 305-310.

Sur, M., Nagakura, I., Chen, N., Sugihara, H., 2013. Mechanisms of plasticity in the developing and adult visual cortex. Prog. Brain Res. 207, 243-254.

Takata, N., Mishima, T., Hisatsune, C., Nagai, T., Ebisui, E., Mikoshiba, K., Hirase, H., 2011. Astrocyte calcium signaling transforms cholinergic modulation to cortical plasticity in vivo. J. Neurosci. 31(49), 18155-18165.

Thiele, A., 2009. Optimizing brain processing. Nat. Neurosci. 12(11), 1359-1360.

Thiele, A., Herrero, J.L., Distler, C., Hoffmann, K.P., 2012. Contribution of cholinergic and GABAergic mechanisms to direction tuning, discriminability, response reliability, and neuronal rate correlations in macaque middle temporal area. J. Neurosci. 32(47), 16602-16615.

Thienel, R., Kellermann, T., Schall, U., Voss, B., Reske, M., Halfter, S., Sheldrick, A.J., Radenbach, K., Habel, U., Shah, N.J., Kircher, T., 2009. Muscarinic antagonist effects on executive control of attention. Int. J. Neuropsychopharmacol. 12(10), 1307-1317. 
Thompson, J.C., Stough, C., Ames, D., Ritchie, C., Nathan, P.J., 2000. Effects of the nicotinic antagonist mecamylamine on inspection time. Psychopharmacology (Berl). 150(1), 117-119.

Tremblay, N., Warren, R.A., Dykes, R.W., 1990a. Electrophysiological studies of acetylcholine and the role of the basal forebrain in the somatosensory cortex of the cat. I. Cortical neurons excited by glutamate. J. Neurophysiol. 64(4), 1199-1211.

Tremblay, N., Warren, R.A., Dykes, R.W., 1990b. Electrophysiological studies of acetylcholine and the role of the basal forebrain in the somatosensory cortex of the cat. II. Cortical neurons excited by somatic stimuli. J. Neurophysiol. 64(4), 1212-1222.

Turchi, J., Sarter, M., 1997. Cortical acetylcholine and processing capacity: effects of cortical cholinergic deafferentation on crossmodal divided attention in rats. Brain Res. Cogn. Brain Res. 6(2), 147-158.

Vaucher, E., Hamel, E., 1995. Cholinergic basal forebrain neurons project to cortical microvessels in the rat: electron microscopic study with anterogradely transported Phaseolus vulgaris leucoagglutinin and choline acetyltransferase immunocytochemistry. J. Neurosci. 15(11), 7427-7441.

Volterra, A., Meldolesi, J., 2005. Astrocytes, from brain glue to communication elements: the revolution continues. Nat. Rev. Neurosci. 6(8), 626-640.

Voytko, M.L., Olton, D.S., Richardson, R.T., Gorman, L.K., Tobin, J., Price, D., 1994. Basal forebrain lesions in monkeys disrupt attention but not learning and memory [published erratum appears in J Neurosci 1995 Mar; 15 (3): following table of contents]. The Journal of Neuroscience 14(1), 167-186.

Wang, F., Smith, N.A., Xu, Q., Fujita, T., Baba, A., Matsuda, T., Takano, T., Bekar, L., Nedergaard, M., 2012. Astrocytes modulate neural network activity by $\mathrm{Ca}(2)+$-dependent uptake of extracellular K+. Sci. Signal. 5(218), ra26.

Wenk, G.L., 1997. The nucleus basalis magnocellularis cholinergic system: one hundred years of progress. Neurobiol. Learn. Mem. 67(2), 85-95.

Woody, C.D., Swartz, B.E., Gruen, E., 1978. Effects of acetylcholine and cyclic GMP on input resistance of cortical neurons in awake cats. Brain Res. 158(2), 373-395.

Xiang, Z.X., Huguenard, J.R., Prince, D.A., 1998. Cholinergic switching within neocortical inhibitory networks. Science 281(5379), 985-988.

$\mathrm{Xu}$, H., Jeong, H.Y., Tremblay, R., Rudy, B., 2013. Neocortical somatostatin-expressing GABAergic interneurons disinhibit the thalamorecipient layer 4. Neuron 77(1), 155-167.

Yang, Y., Ge, W., Chen, Y., Zhang, Z., Shen, W., Wu, C., Poo, M., Duan, S., 2003. Contribution of astrocytes to hippocampal long-term potentiation through release of D-serine. Proc. Natl. Acad. Sci. U. S. A. 100(25), 15194-15199.

Zaborszky, L., Csordas, A., Mosca, K., Kim, J., Gielow, M.R., Vadasz, C., Nadasdy, Z., 2015. Neurons in the basal forebrain project to the cortex in a complex topographic organization that reflects corticocortical connectivity patterns: an experimental study based on retrograde tracing and 3D reconstruction. Cereb. Cortex 25(1), 118-137.

Zant, J.C., Kim, T., Prokai, L., Szarka, S., McNally, J., McKenna, J.T., Shukla, C., Yang, C., Kalinchuk, A.V., McCarley, R.W., Brown, R.E., Basheer, R., 2016. Cholinergic Neurons in the Basal Forebrain Promote Wakefulness by Actions on Neighboring Non-Cholinergic Neurons: An Opto-Dialysis Study. J. Neurosci. 36(6), 2057-2067.

Zilles, K., Schröder, H., Schröder, U., Horvath, E., Werner, L., Luiten, P., Maelicke, A., Strosberg, A., 1989. Distribution of cholinergic receptors in the rat and human neocortex, Central cholinergic synaptic transmission. Springer, pp. 212-228. 
Zinke, W., Roberts, M.J., Guo, K., McDonald, J.S., Robertson, R., Thiele, A., 2006. Cholinergic modulation of response properties and orientation tuning of neurons in primary visual cortex of anaesthetized Marmoset monkeys. Eur. J. Neurosci. 24(1), 314-328. 


\section{Figure legends}

Figure 1. Cholinergic modulation of plasticity. (Left, Top) Schematic illustrating BF-enabled, stimulus-specific plasticity in V1 of wild type (WT) mice (Chen et al., 2012). Pairing a visual stimulus (an oriented grating) with electrical stimulation of the basal forebrain (BF) leads to prolonged facilitation of V1 neuron responses to the specific visual stimulus but not other stimuli (denoted by thick red connections between 45 degree oriented stimulus and pyramidal neuron, depicted as triangle). BF stimulation also leads to increased calcium responses from astrocytes (depicted as star), which are mediated by muscarinic ACh receptors (mAChRs) and by $\mathrm{IP}_{3}$ receptor type $2\left(\mathrm{IP}_{3} \mathrm{R} 2\right)$ on astrocyte calcium stores. Astrocyte-mediated effects on neurons engage NMDA receptors (NMDARs). (Left, Bottom) Neuronal responses (shown in red) were measured extracellularly before and after the pairing. Shaded area with black arrow indicates a period of pairing. Increased responses persist for 100s of seconds. (Right, Top) In mice specifically lacking $\mathrm{IP}_{3} \mathrm{R} 2$ receptors in astrocytes $\left(\mathrm{IP}_{3} \mathrm{R} 2\right.$-cKO animals), BF stimulation does not evoke $\mathrm{IP}_{3} \mathrm{R} 2$-mediated calcium increases in astrocytes (blue cross). (Right, Bottom) Pairing BF stimulation with a visual stimulus does not cause stimulus-specific potentiation of V1 neuronal responses (shown in green). Adapted from Chen et al. (2012).

Figure 2. Cholinergic modulation of cortical state. (a) Experimental setup for electrophysiological recordings to reveal the role of $\mathrm{ACh}$ in cortical desynchronization and decorrelation (Chen et al., 2015). In one experiment, the neuronal activator Channelrhodopsin (ChR2) is expressed in ChAT-expressing neurons of the basal forebrain and blue light stimulation over V1 is used to selectively release ACh in V1. In the same mice, the neuronal activity suppressor Archaerhodopsin (Arch) is expressed in somatostatin-expressing V1 neurons, 
and green light stimulation used to selectively suppress SOM neurons. Neuronal responses and LFPs are recorded in V1 before, during and after blue light, or simultaneous blue and green light, stimulation through the objective. (Inset) Image of Arch-GFP expression in V1. Scale bar, 50 $\mu \mathrm{m}$. (b) LFP desynchronization during ChAT-ChR2 stimulation at $\mathrm{t}=0 \mathrm{~s}$ (arrow) (top) is blocked by simultaneous SOM-Arch stimulation (green bar) (bottom). Traces were low-pass filtered $(<5 \mathrm{~Hz})$. Thus, ACh release leads to desynchronization of responses, and activating SOM neurons is critical for mediating the effects of ACh. (c) Schematic illustrating the suggested circuit mechanisms underlying cholinergic modulated temporal dynamics in the superficial layers of V1. The various inhibitory neuron types (including SOM; parvalbuminexpressing, PV; vasoactive intestinal peptide-expressing, VIP; layer 1, L1) have complex inhibitory relationships with one another. PV and SOM neurons inhibit pyramidal (PYR) neurons, while SOM neurons also inhibit PV neurons. Desynchronization and decorrelation of pyramidal neuron responses following $\mathrm{ACh}$ release arises primarily due to the inhibitorydisinhibitory effects of PV and SOM neurons mediated through the action of ACh on SOM neurons. The effect of ACh on VIP and L1 neurons requires higher concentrations of ACh. Green ovals indicate cholinergic receptors. Red and white circles indicate inhibitory and excitatory synapses, respectively. Adapted from Chen et al. (2015). 

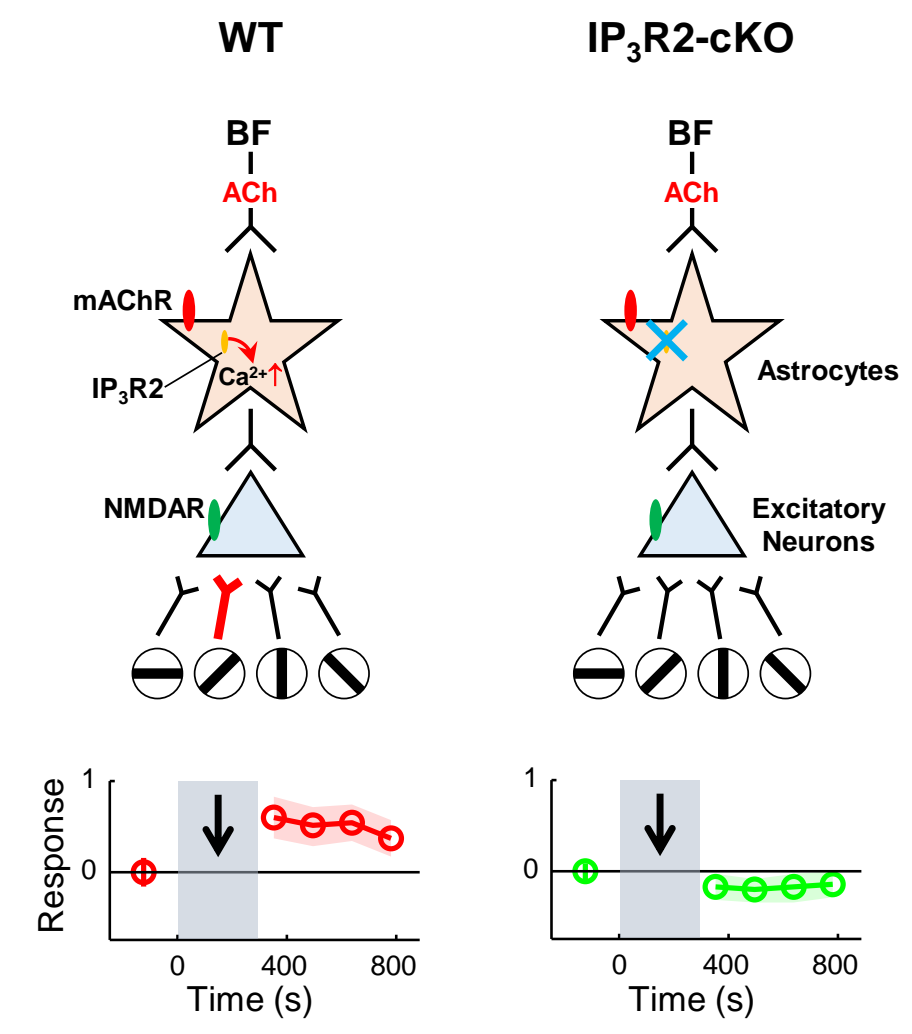
a

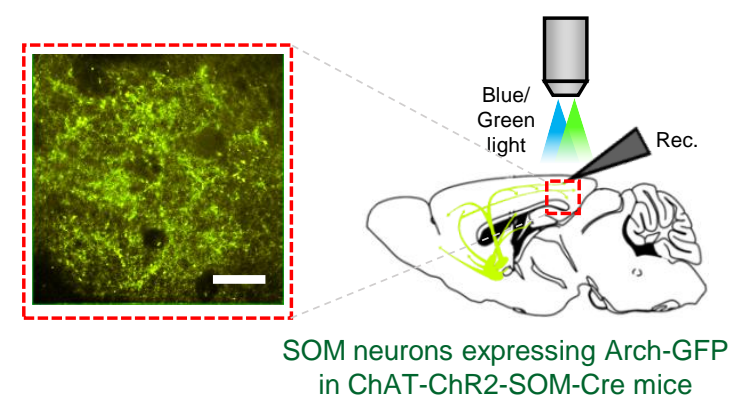

b

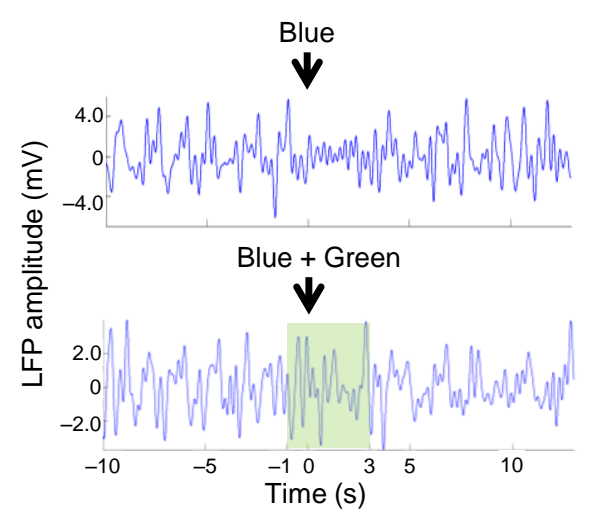

C

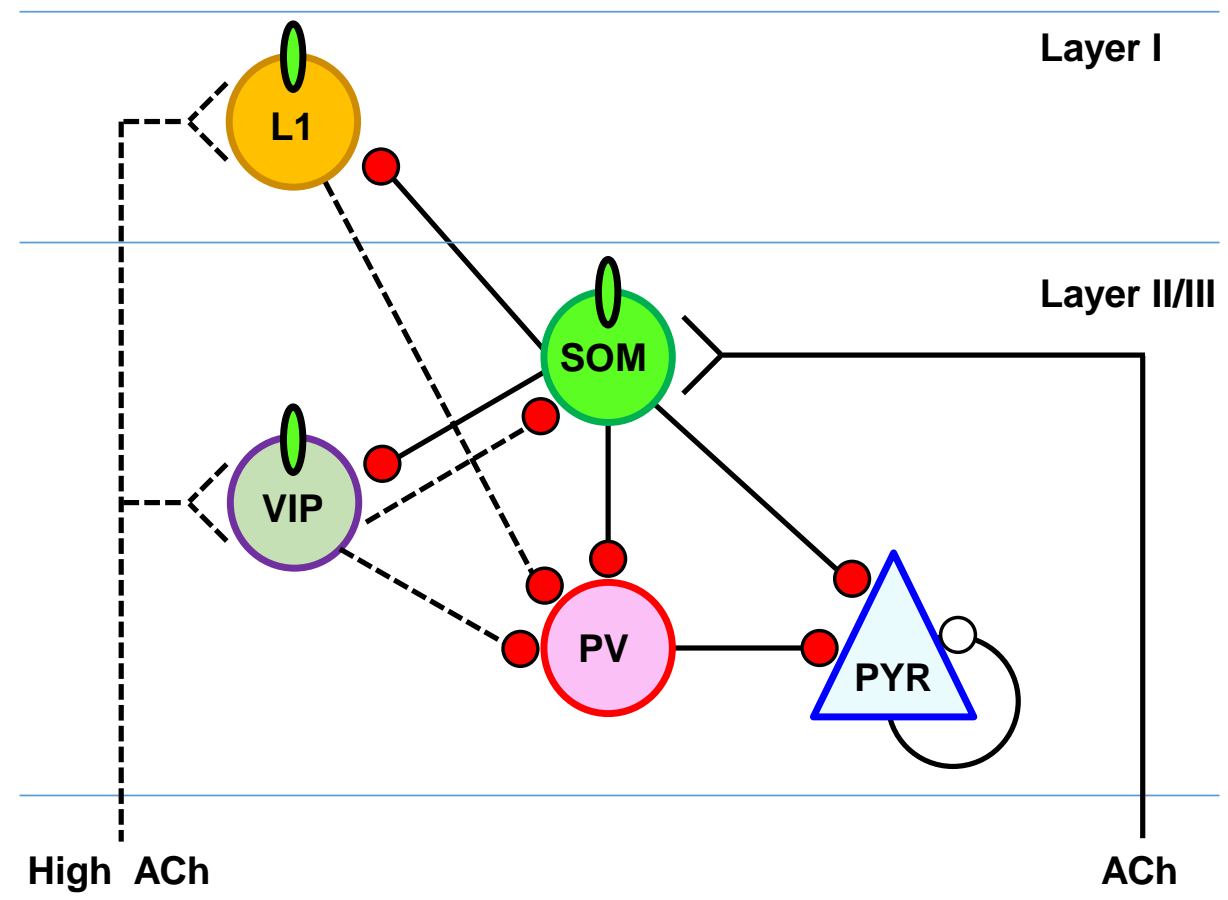

